\title{
An Introduction to Exdysivity Index for Organizational Change Capability Assessment
}

\author{
Yanyong Thammatucharee ${ }^{1 *}$ \\ ${ }^{1}$ Assumption University, Thailand \\ *Corresponding author: Yanyong Thammatucharee: \\ yanyong.thammatucharee@gmail.com
}

\section{Abstract:}

Citation: Thammatucharee $Y$. (2017)An Introduction to Exdysuvity Index for Organizational Change Capability

Assessment.Open Science Journal 2(4)

Received: $2^{\text {nd }}$ October 2017

Accepted: $17^{\text {th }}$ October 2017

Published: $21^{\text {st }}$ November 2017

Copyright:@ 2016 This is an open access article under the terms of the Creative Commons

Attribution License, which permits unrestricted use, distribution, and reproduction in any medium, provided the original author and source are credited.

Funding: The author(s) received no specific funding for this work

\section{Competing Interests: The} author have declared that no competing interests exists.

The dynamic change capabilities of organizations are prerequisite to the success, long-term growth and sustainability (Moran \& Brightman, 2000; Andreeva \& Victoria, 2006; Barreto, 2010; Halkos, 2012). Although organization development (OD) study involves planned changes that would help businesses to stay competitive in the marketplace, there is no effective and reliable change indicator that can reflect the need and level of change capabilities. Apparently, organizational change management requires multi-perspectives approach rather than a single approach to all change situations (Andreeva, 2008). To achieve the successful and sustainable change, an effective change measurement is the key (Moran, Baird \& Brightman, 2000). This study aims to propose the development idea for a change indicator or so-called "exdysivity index (EI)" as the change capability assessment and requirement for change intervention at both international and individual organization level.

Keywords: Change capability, Change assessment, Change indicator, Exdysivity index 


\section{Introduction}

The fast-moving and volatile environment has forced businesses to stay agile and adapt themselves all the time. Historical success cannot guarantee the future existence in the marketplace. Companies with past success may find that their performance drops dramatically due to the lack of sufficient changes to critical facets of business operations and management. Organization change is important and necessary for long-term growth and sustainability.

Organization development (OD) is process that can help organizations build their capacity to change and to achieve effectiveness in terms of financial performance, customer satisfaction and employee engagement (Cummings \& Worley, 2009). The capacity to change is critical to improvement of the competitive advantage which is a key to the success of organizations.

The success of organizations can be assured through the achievement of the goals and targets. Profit organizations focus on the financial achievement in terms of sales, return on investment, profitability, etc. Non-profit organizations focus on the objective fulfillment. However, not many organizations can maintain their competitiveness and sustainability in the long term. Andreeva \& Victoria (2006) suggest that it is difficult to keep competitive advantage for long-term periods without development of the capability to change.

The change capability involves a number of areas for both generic and specific competencies. Organizations need to know what constitutes the change capability. Currently, there is no reliable tool to measure, assess and provide the informative results that can disclose the strengths and weaknesses affecting the change capability of an organization or firm.

As organizational change through the development of change capabilities is necessary for long-term survival (Barreto, 2010; Halkos, 2012), the success of change processes depend on a number of factors, for example: employees' perception of human relationship value (Jones, Jimmieson \& Griffiths, 2005), alignment of the value system (Burnes \& Jackson, 2011), matching of change management strategy with stages to overcome resistance sources (habits and perceived risks) (Aladwani, 2001; Self \& Schraeder, 2009). In order to cope with organizational change successfully, Judge, Thoresen, Pucik \& Welbourne (1999) addressed 7 traits influencing an individual (locus of control, generalized selfefficacy, self-esteem, position affectivity, openness to experience, tolerance for ambiguity, and risk aversion). Coping with organizational change was also related to both extrinsic (salary, job level, plateauing, job performance) and intrinsic (organizational commitment, job satisfaction) career outcomes. Lindell \& Drexler (1979) commented that judgmental measures were still used as indicators of real organizational changes.

However, in order to help drive the organizational change process effectively, a systematically developed indicator can be an alternative. This paper discusses the importance and necessity for OD community to develop a well-established mechanism that helps identify the level of change capacity. The measurement index under the name of "Exdysivity" is developed and proposed for future research. 


\section{Business success and sustainability}

In the rapid changing environment, firms need to react proactively to ensure their distinctive competencies and sustainability. The average period for which firms are able to sustain competitive advantage has decreased significantly over time (Barreto, 2010). Firms find it harder to achieve long-term competitive advantage under hypercompetitive or high-velocity environments. Strategic management suggests what need to be done so that businesses can survive and maintain existence in the marketplace. In general, successful business operation is measured by a number of metrics such as sales growth, profitability and return on investment. It is the prime responsibility of the management to ensure that the operation is at the most efficient and effective level. As a result, the stakeholders are getting the return in the form of dividend, share price capital gain, and so on.

It is important for businesses to understand the importance of change capability as one of the elements to enhance the competitive advantage and longterm survival. It is important for employees and organizations to adapt themselves to ensure the change effectiveness (Halkos, 2012).

What constitute the business success and sustainability?

Moran \& Blauth (2009) argue that vision and strategy have been communicated extensively but day-to-day action is not emphasized enough to get buy-in and engagement. The challenge of the past and today change in view of leader of an organization can be compared as shown in the table 1 - The past and today leaders' view on change (Moran \& Blauth, 2009) below:

Table 1. The past and today leaders' view on change (Moran \& Blauth, 2009)

\begin{tabular}{|l|l|}
\hline In the past, leaders ... & Today, leaders ... \\
\hline $\begin{array}{l}\text { - Counted on periods of stability between } \\
\text { major changes. }\end{array}$ & $\begin{array}{l}\text { - Face one change after another, } \\
\text { or several at once. }\end{array}$ \\
\hline - Assumed that change took time. & - Need quick wins to build momentum. \\
\hline $\begin{array}{l}\text { - Treated change as a process with a } \\
\text { beginning, middle, and end. }\end{array}$ & $\begin{array}{l}\text { - See constant change as the permanent } \\
\text { business landscape. }\end{array}$ \\
\hline $\begin{array}{l}\text { - Saw change management as a } \\
\text { specialized job. }\end{array}$ & $\begin{array}{l}\text { - See change management as } \\
\text { everyone's job. }\end{array}$ \\
\hline $\begin{array}{l}\text { - Applied a similar approach to every initiative. } \\
\text { - Saw change as linear, one phase after } \\
\text { after another. }\end{array}$ & $\begin{array}{l}\text { - Tailor an approach for every initiative. } \\
\text { phases occurring at the same time. }\end{array}$ \\
\hline $\begin{array}{l}\text { - Gained support by communicating a clear } \\
\text { business case. }\end{array}$ & $\begin{array}{l}\text { - Gain support by communicating truths that } \\
\text { have an impact on effort and emotions. }\end{array}$ \\
\hline $\begin{array}{l}\text { - Succeeded by delivering value to customers. } \\
\text { puliver value by responding quickly to } \\
\text { threats and opportunities. }\end{array}$ \\
\hline
\end{tabular}




\section{Organizational change capability}

The term used to describe the ability or capacity to change of an organization varies with extended difference to certain extent such as organizational capacity for change (OCC) (Judge \& Elenkov, 2005), dynamic change capability (Andreeva \& Victoria, 2006), dynamic capabilities (Barreto, 2010). Barreto (2010) proposes the definition of dynamic capability as "the firm's potential to systematically solve problems, formed by its propensity to sense opportunities and threats, to make timely and market-oriented decisions, and to change its resource base."

The construct of organizational change capacity can be conceptually grouped into eight dimensions (Judge, W.Q. \& Elenkov, D., 2005) as follows:

1. Trustworthy leadership: The ability of senior executives to earn the trust of the rest of the organization and to show the members of the organization the way to meet its collective goals.

2. Trusting followers: The ability of the rest of the organization to constructively dissent and/or enthusiasm.

3. Capable champions: The ability of an organization to attract, retain, and empower change leaders to evolve and emerge.

4. Involved mid-management: The ability of middle managers to effectively link senior management with the rest of the organization.

5. Innovative culture: The ability of the organization to establish norms of innovation and encourage innovative activity.

6. Accountable culture: The ability of the organization to carefully steward resources and successfully meet predetermined deadlines.

7. Systems communications: The ability of the organization to communicate vertically, horizontally, and with customers.

8. Systems thinking: The ability of the organization to focus on root causes and recognize the interdependencies within and outside the organizational boundaries.

The discussion of strategy to sustainable success of a firm has been widely discussed in the past two decades. Andreeva \& Victoria (2006) argue that the organization's ability to sustain and renew its competitive advantages is most important under the continuously changing environment. Kruasom \& Saenchaiyathon (2014) addressed the competitive advantage created from resource-based view with key strategies consisting of knowledge management capability, technological capability, innovative capability, and human resource capability.

What kind of change is important to the company's success and survival?

According to the research by several authors, the following are examples of key organizational change capabilities (Andreeva \& Victoria, 2006; Halkos, 2012).

- Superior product development and innovation

- Business model change

- Merger and acquisition integration

- Work process change and improvement (Trkman, 2010).

Some changes are generic and some are specific resulting in enhanced competitive advantages. However, change activities can be imitated by other 
organizations. Knowledge of change activities can be transferred through employees who moved from one company to another. Thus the focus should not be put only on what to change but also how to change. This could form a core capability of the organization. The elements of change capability should be identified so that they are improved for contribution to the performance of the organization.

Andreeva \& Victoris (2006) suggest that the change capability of an organization consists of 3 steps:

1) To see new opportunities for change development.

2) To realize what changes are needed.

3) To implement the changes successfully.

Berreto (2010) suggests that dynamic capabilities evolve through mechanisms including learning, knowledge articulation, knowledge codification, trial and error, improvisation, and imitation.

\section{How to determine the success level of change capability}

In respect of all organizational change efforts performed, there is apparent aspect that the success rate is relatively low. Burnes \& Jackson (2011) argue that there is substantial evidence that approximately $70 \%$ of all change initiatives fail. The risk of failure is greater than before (Moran \& Brightman, 2000) such as in merger and acquisition (M\&As) (Schraeder \& Self, 2003). Measurement is key to successful and sustainable change (Moran \& Brightman, 2000). The more an organizational goals can be quantified and progress toward these goals linked to individual performance, the more successful and long-lasting change is likely to be.

Key performance indicators (KPIs) are used by many organizations for performance measurement and control. Two common KPIs that have been used for management purpose are productivity and efficiency. As change capability becomes one of the key success factors, it is worth considering how to determine the success of change efforts and interventions through the dynamic change capabilities.

Most studies of change capability do not discuss on how an organization will know its change capability. There should be a reliable tool that can help assess the level of the change capability of an organization so that it can be compared with other competitors (Sullavan, 2000). With competition, organizations will thrive to become better than what they are or continue keeping the high level from dropping down.

For stakeholders, the change capability indicator can become the target that can reduce the risks of lower performance and increase the confidence of the organization's management to survive in the long term. 


\section{Action value and action plan}

It is substantially challenging to translate a sustainability strategy into action and drive it through a complex organization (Epstein \& Roy, 2001). Chrusciel \& Field (2006) identified action plan that addresses the critical factors for dealing with changes can increase the chance of successful change transformation. The action is important especially as the feedback after the assessment. Piderit (2000) argued that the change process should be egalitarian by fostering ambivalent attitudes toward change. The process of organizational change should include top-down, planned change and bottom-up approach.

\section{Emergence of exdysivity index}

Volberda (1996) identified hyper-competition as the force that moves firms to be more quickly and boldly in making change.

How well an organization can renew its change capabilities? It is a continuous cumulative process to achieve fast-changing, unpredictable, and complex environment. Exdysivity is natural change process which can be cultivated in an organization to become operational routine. Exdysivity imitates the skin shedding of reptiles such as snake that naturally renew its skin many times a year for growth and more beautiful skin. Exdysivity focuses on action taking in the most natural manner as without action, changes cannot happen. High exdysivity organization needs to be proactive in developing the change capability and serve as a basis for competitive advantage.

The main focus under exdysivity is action. Each action has impact to the operation contributing to growth and success of an organization. A different action renders different economic value. Without actions, value creation is unforeseeable.

How to improve the exdysivity of an organization?

This involves people skills, management system and organizational infrastructure such as information system, communication system and human resource development system. In order for an organization to manage the change process, the Malcom Baldrige's criteria for performance excellence suggested leadership, strategic planning, customer and market focus, information and analysis, human resource focus, process management, and benefit results as the framework (Chrusciel \& Field, 2003).

The exdysivity index consists of a set of measurement criteria that will be used to assess an organization. The major change capability areas under assessment include:

- Strategic planning and execution capability

- Resource management and development capability

- Change culture and mindset institution capability

- Action efficiency and effectiveness capability

- Realization of growth, success, problem and failure capability

As an organization needs to embrace change management as its competitive advantage, elements of change capability can contribute to the success of the organization by achieving the targets for both financial and non-financial. The 
change process will take into account the fast-changing environment and operational change improvement (see figure 1 - The relationship of exdysivity and change capability on organization target).

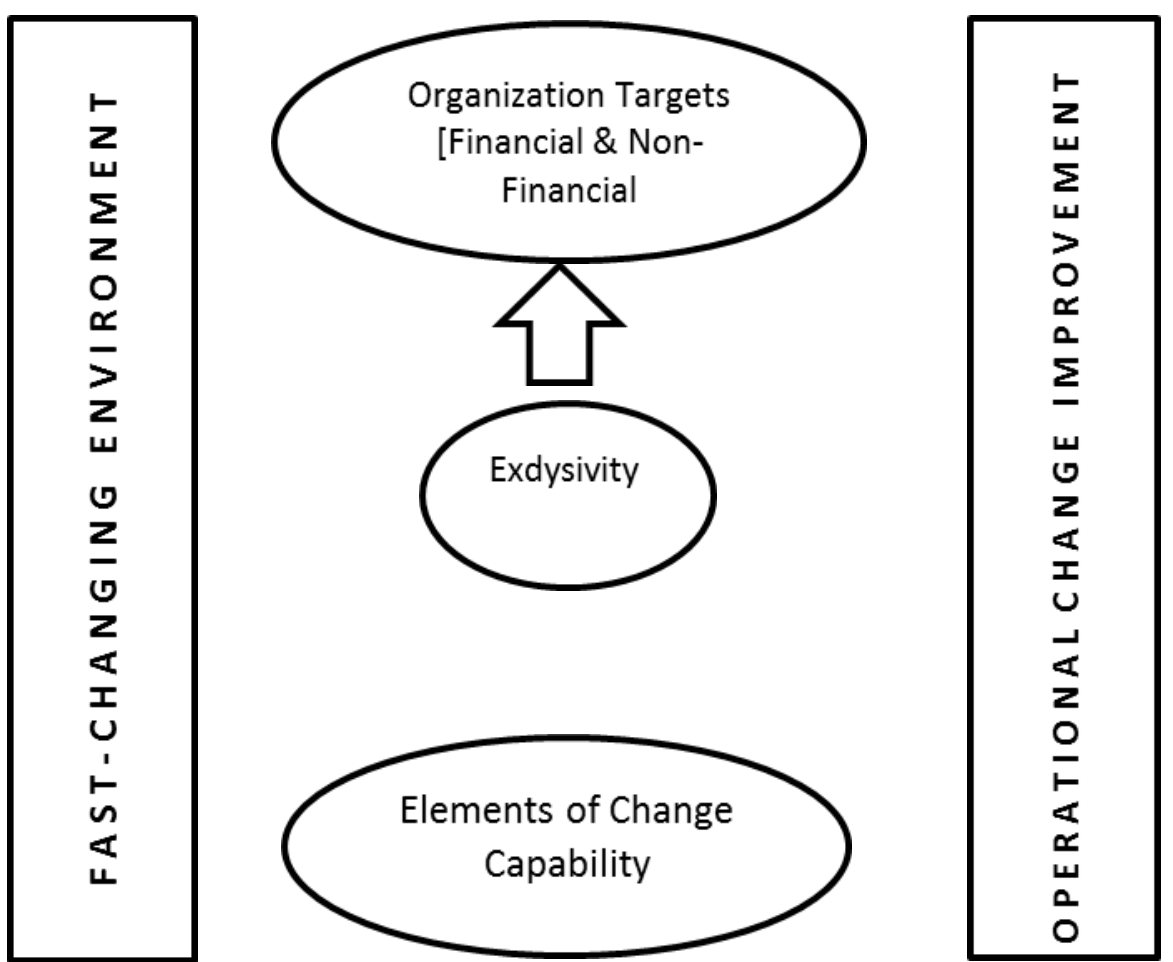

Figure 1 - The relationship of exdysivity and change capability on organization target

Exdysivity represents the quality of change competency that evolves and becomes part of a firm's operation routines in the natural manner. Based on the above discussion on several academic opinions and researches, I propose the word 'Exdysivity' to represents one of an organization's capabilities and part of the competitive advantages in addition to the existing terminology of productivity and efficiency.

In order to understand the current status of an organization with regard to change capability, a systematic assessment should be developed and results should be disclosed so that necessary changes and interventions can be designed for improving the weaknesses or strengthening the strengths. The exdysivity level determination of an organization can be done through the conceptual criteria as shown in figure 2 - overview conceptual criteria for assessment of a firm's exdysivity below.

There are 5 distinctive criteria under the assessment process as follows:

1. Strategic planning and execution - To become successful, organizations need to develop effective and powerful strategies in order to guide people to towards the achievement of the targets and goals. The formulated strategies have to be based on the capabilities of the organization with a clear-cut time line of the execution and implementation of related plans (Chrusciel \& Field, 2006). 
2. Resource management and development - The available resources of an organization should be efficiently utilized to maximize the potential through effective management and operations (Yeung \& DeWoskin, 1998). Resources cover both tangible and intangible. In this case human resource is considered one of the most valuable assets of the organization. The capability to use and develop existing resources is crucial for the success of the organization.

3. Change culture and mindset institution - In order for change to become part of an organization's best practices, appropriate OD interventions including the readiness for change through employees' perceptions of organizational culture (Jones, Jimmieson \& Griffiths, 2005) should be made to institute the change culture and mindset for the people or in other word, the inner shift in people's value, aspirations, and behaviors (Karp, 2004; Nah \& Lau, 2001). This requires extensive challenge to the status quo and stimulus for change processes. Without natural change as part of the working culture, it could be difficult for an organization to maintain the effective capabilities.

4. Action efficiency and effectiveness - Most past researches on change and dynamic capabilities or abilities do not focus on action taking and consider it as the key to the success of the capability development process. Action science needs further research so that the effectiveness of any concepts to be applied to an organization can be assured.

5. Realization of growth, success, problem and failure - It is important or an organization to keep close monitoring on the development and improvement of the capabilities. Measuring the result of the performance can lead to understanding and adjusting the strategy, plan and action that will better respond to the fast-changing environment (Chrusciel \& Field, 2006).

\section{Overview Conceptual Criteria for Assessment of a Firm's Exdysivity}

Exdysive Change Capabilities

Strategic planning \& execution

Resource management \& development

Change culture \& mindset institution

Action efficiency \& effectiveness

Realization of growth, success, problem and failure

\section{Past}

\begin{tabular}{|l|}
\hline Analysis and \\
Review of \\
historical \\
performance \\
in comparison \\
with plan, \\
target, \\
competitors \\
and industry. \\
\hline
\end{tabular}

Present

\begin{tabular}{|l|}
\hline Evaluation of \\
current \\
operation \\
status status, \\
mornitoring, \\
and resonse to \\
environment \\
changes. \\
\end{tabular}

Future

Assess the possibility and reliability of future plan, project and initiative commitment for natural changes.

Figure 2 - overview conceptual criteria for assessment of a firm's exdysivity

Change process should address how a firm has created value from the past, present and future for its customers and other stakeholders (Karp, 2004). In term of the time dimensions, the assessment should be done in the manner that covers 3 major period of time i.e. past, present and future. The time interval should be 
traced back to at least 5 years. The present period may cover the current year to date. The future period can cover the next 3 to 5 years.

The past time-frame assessment will be focused on the analysis and review of historical data to understand the performance in relevant areas. This may be started from the review of the financial performance such as sales, expenses, profit and loss. It can be expanded to cover other functions within an organization such as production, sales and marketing, human resource, logistics, information technology and so on.

The present time-frame assessment aims at understanding the current status and how the responsible people within an organization react to the opportunity and threat. The environmental changes can be a critical factor that triggers the actions to be made. Thus the assessment of what is going on can give an impression of the up-to-date capability of the organization.

The future time-frame assessment can help the evaluator to understand the capability of an organization in forward looking perspective and assess the propensity of the action taking by individual under each function and the team itself. The future planned capability development can help confirm the consistency and continuity of the competitive advantages that the organization has developed and maintained for long-term sustainability.

The above conceptual assessment criterial should be supported by more details that should be designed in the more systematic way and with appropriate weight to be assigned to each checking items. The reliability of the measurement needs to be confirmed through the sufficient test activities before the methodology can be applied to the real system. Smith (2002) suggested success rates by type of measure as shown in table 2 below.

Table 2: Success Rates by Type of Measure

\begin{tabular}{|l|l|}
\hline \multicolumn{1}{|c|}{ Category } & \multicolumn{1}{c|}{ Sample Measures } \\
\hline Rating of Overall Success & Satisfaction with change, stakeholder expectations met \\
\hline Project Management & $\begin{array}{l}\text { Implementation scored against "world-class standards," } \\
\text { project completed on time, on budget, with promised } \\
\text { features; unanticipated negative consequences }\end{array}$ \\
\hline Operations Performance & $\begin{array}{l}\text { Cost reduction, cycle time reduction, productivity gain, } \\
\text { product/service quality, rate of product introductions, rate } \\
\text { of technology deployment, employee morale improvement }\end{array}$ \\
\hline Customer & Customer satisfactions, sales \\
\hline Enterprise Performance & $\begin{array}{l}\text { Earnings, ROE, revenue growth/loss, operating profit, } \\
\text { market share/penetration, competitive edge, customer } \\
\text { loss, cash flow, stock price }\end{array}$ \\
\hline Owner & Shareholder value (dividend plus stock appreciation) \\
\hline
\end{tabular}


Once the instrument of the change capability measurement has been confirmed for its acceptance and reliability, the methodology and application can be started with consequences and reaction from the target organization. The expectation from the test result is comments and suggestions that the assessment body provides. This can lead to further improvement plan or interventions needed.

The final result from the assessment activity can be in the form of an index. This index score ranges from 0.00 to 100.00 representing the level of change capability or exdysivity level. The highest exdysivity level is 100.00. Each capability has to be examined and measured with different weight to be assigned under each category before calculation to form the total score as per the designed formula. A report should be provided with explanation and suggestion for further improvements.

\section{Case Study and Discussion}

A qualitative research with a Thai retail company had been performed from 2014-2017 (disguised name "AA company"). This case study is an example for a change capability effort that led to the consequences and results at the end of the study.

AA company has been in fashion retail business for over 30 years in Thailand. It had grown up and passed difficult time during instable political period and the financial crisis in 1997. The company realized that the business was at risk of domestic uncertainty that affected the sales and performance from time to time. One strategy that the management selected was to expand the business overseas so that the revenue would not rely solely on domestic sales.

After 2 years of feasibility study and due diligence activity, the company got approval from the board of director to acquire a group of companies in Malaysia (disguised name "BB company") with similar kind of business. BB company had been in fashion business in Malaysia for over 20 years with their own developed brands.

In the first year after acquisition, the company needed to change the ERP system to comply with the GST (Goods and Services Tax) law which was firstly introduced effectively from 1 April 2015. The parent company (AA) had invested on SAP system which was complicated and quite high investment as compared to the proposed local cheaper one.

After reviewing the business plan in 2014, the Thai country manager proposed to liquidate a shoe brand which had incurred continued loss for several years. This decision was made after taking into consideration the competitiveness and future growth plan that it was not worth continuing the business.

In view of the management at AA, the inventory level and its aging was very high and needed urgent improvement. The buying budget was reduced and more clearance sale events had been implemented. At the same time, the design of the new products and the merchandise development had been centralized and controlled tightly.

The changes had caused resistance and challenges from local staffs in Malaysia. At the same time, the sales had dropped continuously since the start of 
GST and also with higher competition from new brands and fierce price reduction. Some competitors launched significantly higher portion of low price range of new products.

The cost at $\mathrm{BB}$ started to climb up with higher cost in new system and additional implementation of POS (point of sales) at all counters. The management fees from Thailand representing the allocated cost of the management at AA had been charged to BB. This resulted in deteriorating performance, especially the bottom line.

Cost reduction plan had been introduced. This started from no salary adjustment and lower bonus in 2016. MSS (Mutual Separation Scheme) was introduced with expectation of reduced operational costs. This caused higher attrition rate as employees started looking for new jobs with higher salary and more secured job.

In 2015 the restructuring was made at AA at the top management level including the CEO and CFO positions. Shortly after that, the country manager in Malaysia had been replaced by local person from outside. This caused the old staffs with low morale and finally the resignation of key management increased higher.

\section{Discussion}

The case study demonstrated the development of change efforts by both companies during the past 3 years in relation to the continuous changing environment. However, the consequences did not lead the companies to the better performance. BB company still struggled to survive from the economic difficulties. AA company had to consolidate the performance of BB company to the total group financial statement. It could be possible that the companies did not see clearly the critical success factors (CSF) for the project (Muller \& Jugdev, 2012) and what areas of change that urgently needed attention (Gersick, 1991). In addition, certain improvement initiatives might need higher priority than others. That means the change content ('what needs to be changed') has influenced the change implementation method (Andreeva, 2008). Moreover, the launching of too many changes such as the new ERP system and re-organization has increased the stress to employees due to higher workload making change less attractive and this could lead to the failure of the change interventions (Vakola \& Nikolaou, 2005). When implementing change, the management needs to be aware of the ways that personal issues can impact on employees' thought, feelings and behavior. According to Bovey \& Hede (2001), a balanced approach to changes is necessary - both technical and human factors including unconscious processes such as defense mechanisms. In order to be successful at ERP implementation, Nah \& Lau (2001) suggested 11 factors found critical consisting of 1). ERP teamwork and composition. 2). change management program and culture. 3). Top management support. 4). Business plan and vision. 5). Business process reengineering with minimum customization. 6). Project management. 7). Monitoring and evaluation of performance. 8). Effective communication. 9). Software development, testing and troubleshooting. 10). Project champion. 11). Appropriate business and IT legacy systems. If there was a tool that could help assess the total company's change requirements, it might help both companies to 
allocate proper resources to the important things first. Schraeder \& Self (2003) suggested that the overall evaluation process for the merger and acquisition (M\&A) should put more efforts to assess the cultural compatibility or fit prior to the engagement of two firms. That means making change alone is not enough for a company to survive in the long term. It is the matter of what needs to be changed and how it can be done to really deliver the positive results.

\section{Conclusion}

This paper reviews the importance of the organizational change capabilities from the researches mostly done in early of $21^{\text {st }}$ century.

According to this study, a number of criteria for measuring the exdysivity of an organization were identified. Even though the developed systematic tool has not been tested in real setting, it proposed a challenging and potentially high impact to the OD community. A number of tests to be performed can be used as a reference for further study and development and expectedly can contribute to business community for better and sustainable performance which results in the reasonable return for all stakeholders.

Exdysivity index can be applied for assessment of an organization's capability and effectiveness in pursuing the change process and change management. The result of the assessment can identify both strength and weakness areas that an organization should focus on. The disclosed area for improvement can lead to the development of best practices for the benefits of the organization.

The development a reliable tool and system to disclose the ability to change of organizations become a challenge under today's volatile and fast-moving environment. A lot of research and development needs to be done in order to call for wider attention for interested academic people.

This study opens up an opportunity for future research in respect of the development of reliable tool for the assessment of organizations on their capability to adapt and response to change. The benefits from this proposed index can lead to other related topics worth further research. However, sufficient fund is needed to support the survey that can establish the acceptable confidence level of the result.

\section{References:}

Aladwani, A. M. (2001). Change management strategies for successful ERP implementation. Business Process Management Journal. 7(3), 266-275.

Andreeva, T. (2008). Can organizational change be planned and controlled? Evidence from Russian companies. Human Resource Development International. 11(2), 119-134.

Andreeva, T., \& Chaika, V. (2006). Dynamic capabilities: what they need to be dynamic? Discussion Paper \#10(E)-2006. Institute of Management, St. Petersburg State University: SPb.

Barreto, I. (2010). Dynamic Capabilities: A Review of Past Research and an Agenda for the Future. Journal of Management, 36:256.

Bovey, W., \& Hede, A. (2001). Resistance to organizational change: the role of defense mechanisms. $16(7), 534-548$.

Burnes, B., \& Jackson, P. (2011). Success and failure in organizational change: an exploration of the role of values. Journal of Change Management, 11(2), 133-162. 
Chrusciel, D., \& Field, D. W. (2003). From critical success factor into criteria for performance excellence - an organizational change strategy. Journal of Industrial Technology. 19(4), 1-11.

Chrusciel, D., \& Field, D. W. (2006). Success factors in dealing with significant change in an organization. Business Process Journal, 12(4), 503-516.

Cummings, G.T., \& Worley, G.C. (2009). Organization Development \& Change. Ohio: South-Western Cengage Learning.

Epstein, M. J., \& Roy, M. (2001). Sustainability in action: identifying and measuring the key performance drivers. Long-Range Planning. 34, 585-604.

Gersick, C. J. G. (1991). Revolutionary change theories: a multilevel exploration of the punctuated equilibrium paradigm. Academy of Management Review. 16(1), 10-36.

Halkos, G. (2012). Importance and influence of organizational changes on companies and their employees. MPRA Paper No.36811. Retrived from http://mpra.ub.uni-muenchen.de/36811/

Jones, R. A., Jimmieson, N. L., \& Griffiths, A. (2005). The impact of organizational culture and reshaping capabilities on change implementation success: the mediating role of

readiness for change. Journal of Management Studies. 42(2), 361-386.

Judge, T. A., Thoresen, C. J., Pucik, V., \& Welbourne, T. M. (1999). Managerial coping with organizational change: a dispositional perspective. Journal of Applied Psychology, 84(1), 107-122.

Judge, W.Q., \& Elenkov, D. (2005). Organizational capacity for change and environmental performance: an empirical assessment of Bulgarian firms. Journal of Business Research, 58, 893901.

Karp, T. (2004). Unpacking the mysteries of change - mental of modelling. Article - Mental Modelling of Value Creation. Ruchmore.

Kruasom, T., \& Saenchaiyathon, K. (2014). Achievement a sustainable competitive advantage on the integration of resource-based view and dynamic capacity.

Globalilluminator. Full paper proceeding TMBER-2014, 1, 91-98. Retrieved from http://creativecommons.org/license/by-nc-nd/4.0/

Lindell, M. K., \& Drexler, J. A. Jr. (1979). Issues in using survey methods for measuring organizational change. Academy of Management Review. 4(1), 13-19.

Moran, J. W., \& Brightman, B. K. (2000). Leading organizational change. Journal of Workplace Learning: Employee Counselling Today. 12(2), 66-74.

Moran, L., \& Blauth, C. (2009). Creating a change-capable workforce. Achieveglobal www.achieveglobal.com V3.0(01/2009).

Muller, R., \& Jugdev, K. (2012). Critical success factors in projects: Pinto, Slevin, and Prescott - the elucidation of project success. International Journal of Managing

Projects in Business. 5(4), 757-775.

Nah, F. F., \& Lau, J. L. (2001). Critical factors for successful implementation of enterprise systems. Business Process Management Journal. 6(3), 285-296.

Piderit, S. K. (2000). Rethinking resistance and recognizing ambivalence: a multidimensional view of attitudes toward an organizational change. Academy of Management Review.

25(4), 783-794.

Schraeder, M., \& Self, D. R. (2003). Enhancing the success of mergers and acquisitions: an organizational culture perspective. Emerald Management Decision. 41(5), 511-522.

Self, D. R., \& Schraeder, M. (2009). Enhancing the success of organizational change: matching readiness strategies with sources of resistance. Emerald Leadership 83

Organization Development Journal. 30(2), 167-182.

Smith, M. E. (2002). Success Rates for Different Types Organizational Change. Retrieved from http://www.ispi.org

Sullivan, M. (2000). An instrument to assess organizational change capabilities for e-business transformation (Master's thesis, Worcester Polytechnic Institute,

Massachusetts, USA).

Thammatucharee, Y. (2010). Exdysivity - An Introduction to a New Management Concept. Charleston, USA: Createspace.

Trkman, P. (2010). The critical success factors of business process improvement. International journal of information management. 30(2010), 125-134.

Vakola, M., \& Nikolaou, I. (2005). Attitudes towards organizational change: what is the role of employees' stress and commitment? Emerald Employee Relation. 27(2), 160-170.

Volberda, H. (1996). Toward the flexible form: how to remain vital in hypercompetitive environments. Organization Science. 7(4), 359-374.

Yeung, A., \& DeWoskin, K. (1998, July). From survival to success: the journey of corporate transformation at Haier. Paper presented in the Davidson Institute Research Workshop. 